is associated with high standardised mortality ratio may be different correspondingly.

The point really was to progress from the obvious fact that a standardised mortality ratio of 140 for disease $A$ is not necessarily the same as a proportional mortality rate of 140 for disease $B$ in an epidemiological sense. What West was telling us was that the similarity can be tested by examining the relation of diseases $A$ and $B$ with respect to total mortality.

Perhaps it was unfortunate to discuss this idea with examples we understand as well as smoking. However I think it is clearer when it is emphasised that to suggest that smoking does just bring forward someone's death from coronary heart disease by an average of 20 years is not to excuse cigarettes as a cause. Nor does it necessarily imply that such a relation is extenuated by age. They just become a different kind of cause than if the person died from lung cancer because of smoking, but otherwise would have died, years later, of something else. The notion is that without smoking such a person would only rarely die of lung cancer, even in 300 years.

Radcliffe Infirmary,

KLIM MCPHERSON Oxford OX2 6HE

\section{Low back pain and cancer}

SIR,-Mr R P Cole (3 October, p 840) describes two patients in whom the diagnosis of testicular tumour was delayed because the presenting symptom was back pain. This particular diagnostic trap was described by Dr Cantwell and colleagues, ${ }^{1}$ who identified para-aortic lymphadenopathy as the usual cause of the pain. We believe, however, that the more important lesson to be learnt is that any tumour can present in this way.

We have recently described 10 patients with cancer who presented with backache. ${ }^{2}$ In our study the syndrome of persistent back pain, which was severe enough to prevent sleep and characteristically relieved by sitting forwards, accompanied malignant retroperitoneal lymphadenopathy. Young patients presenting in this way should be closely questioned for symptoms of weight loss and night sweats. Full examination is required to detect superficial lymphadenopathy and testicular or pelvic. abnormalities. Spinal movements and radiographs are typically normal, but a raised erythrocyte sedimentation rate may be mistakenly attributed to spondylitis (as in Mr Cole's second case). Ultrasound scanning usually shows the retroperitoneal lymphadenopathy, ${ }^{3}$ although computed tomographic scanning is useful in difficult cases.

Potentially curable cancers, including leukaemia, ${ }^{4}$ lymphoma, and cervical and testicular tumours, can present with back pain in young people, ${ }^{2}$ so an increased awareness of this syndrome could save lives.

Imperial Cancer Research Fund, London WC2A 3PX

Department of Medical Oncology,

Penella J Woll

Glasgow G12 9LX

1 Cantwell BMJ, Mannix KA, Harris AL. Back pain-a presentation of metastatic testicular germ cell tumours. Lancet 1987;i: 262-4.

2 Woll PJ, Rankin EM. Persistent back pain due to malignant lymphadenopathy. Ann Rheum Dis 1987;46:681-3.

3 Smith D, Johnson R, James RD, Thatcher N. Upper abdominal lymphadenopathy as first presentation of relapse, identified by ultrasonography, in patients treated for small cell (oat cell) bronchogenic carcinoma. Br f Dis Chest 1985;79:141-6.

4 Rogalsky RJ, Black GB, Reed MH. Orthopaedic manifestations of leukemia in children. F Bone foint Surg [Am] 1986;68: 494-501.
Tobacco and end stage diabetic nephropathy

SIR,-Drs Bemd Stegmayr and Folke Lithner (5 September, $p$ 581) report an association between smoking and diabetic nephropathy in a small group of patients. Before a causal relation can be assumed, however, it is important to establish whether or not there were differences in other possible risk factors between the smokers and nonsmokers. In particular, were there any major differences in long term glycaemic control? Smokers may show differences in their attitude to their illness or in socioeconomic state, and these factors could, in turn, influence diabetic control.

Department of Medicine,

Prince of Wales Hospital

Chinese University of Hong Kong,

Hong Kong

AUTHORS' REPLY, -Unfortunately there were no glycosylated haemoglobin $\left(\mathrm{HbA}_{1 \mathrm{c}}\right)$ measurements for some of the uraemic patients, but our impression from blood and urine concentrations of glucose in this group of patients was that there was often unsatisfactory metabolic control.

For the 22 controls, however, we calculated the mean $\mathrm{HbA}_{\mathrm{lc}}$ value during the past seven years. There was a slight inverse correlation between the $\mathrm{HbA}_{\mathrm{lc}}$ value and the latest measured creatinine clearance $(n=22, r=-0.495, p<0.05$, two tail). Student's $t$ test for intergroup difference of $\mathrm{HbA}_{\mathrm{lc}}$ concentration in controls who never smoked compared with those who were smokers or ex-smokers was not significant $(t=1 \cdot 165)$. The intergroup difference was significant $(t=2.93, \mathrm{p}<0.01)$ when mean $\mathrm{HbA}_{\mathrm{lc}}$ values for controls with albuminuria of more than $50 \mathrm{mg} /$ day (mean value $=11 \cdot 74$, $\mathrm{SD}=1.60$ ) were compared with those with less albuminuria (mean value $=10 \cdot 0, \mathrm{SD}=1 \cdot 05$ ).

An arguable point is that diabetic patients who have never smoked may also have taken greater care of themselves in other respects, such as through metabolic and blood pressure checks. A previous case-control study of smoking and nonsmoking diabetics showed a higher prevalence of proliferative retinopathy and macroproteinuria in the smoking group, while there were no intergroup differences in hypertension or glycosylated haemoglobin values.

BERND STEgmayr FOLKE LITHNER

Department of Medicine,

University Hospital

-901 85 Umeå,

Sweden

1 Mühlhauser I, Sawicki P, Berger M. Cigarette-smoking as a risk factor for macroproteinuria and proliferative retinopathy in type I (insulin-dependent) diabetes. Diabetologia 1986;29: 500-2.

\section{Is schizophrenia a neurodevelopmental disorder?}

SIR,-Professor Robin M Murray and Dr Shôn W Lewis (19 September, p 681) have proposed an interesting hypothesis for the aetiology of schizophrenia. This neurodevelopmental hypothesis is based on two notions: the high prevalences of a history of perinatal complications and of abnormalities on computed tomography in schizophrenic patients. They fail to mention, however, that neither of these two abnormalities is specific to schizophrenia, ${ }^{1}$ and patients with severe affective disorders including young manic depressive and delusional depressive patients show abnormalities on computed tomography. ${ }^{23}$ Moreover, the epidemiology of these abnormalities has not been ascertained.

It is also uncertain from their article what type of schizophrenia they refer to in view of the enormous controversy over its definition, with 10 differen available definitions and the widely accepted notion that schizophrenia is a heterogenous disorder more recently subdivided into types 1 (acute) and 2 (chronic). It is difficult to reconcile such a hypothesis with the finding of similiar prevalence rates of schizophrenia in various countries, including developing countries reported in the World Health Organisation international pilot study of schizophrenia.

If perinatal complications are of causal importance then a higher prevalence of the illness migh be expected in developing countries. More intriguing has been the finding that schizophrenia has a more favourable prognosis in developing countries, which has been attributed to the relative integrity of family and social networks in those communities.

The neurodevelopmental hypothesis is also diffcult to reconcile with the genetic basis of this disorder, which the authors have strongly affirmed in their opening remarks. It is conceivable that the neurodevelopmental process might affect brain structures and functions that mediate the effects of genetic factors. The aetiology of temporal lobe epilepsy could serve as a model for an interaction between an early insult causing selective brain damage (febrile convulsion) and a genetic disposition: temporal lobe epilepsy has been associated with the development of schizophrenia-like psychoses, and temporal lobe epilepsy and schizophrenia are both associated with neuropathologica changes affecting the temporal lobe.

An alternative hypothesis to explain the association of schizophrenia with perinatal complication and abnormalities on computed tomography would consider the possibility that selective brain damage is caused by perinatal complications and explain the scan abnormalities and cognitive deficits commonly found in chronic schizophrenia (type 2) This brain damage is a non-specific predisposing factor while the genetic component accounts for the positive symptoms of the illness (type 1 ). This hypothesis suggests that the negative symptoms of the illness are unrelated to schizophrenia itself but substantially contribute to its outcome: these cognitive deficits put the patient at a greater biological disadvantage and compound the degree of associated disability and handicap caused by the positive symptoms of the illness. After all, schizophrenia is "a notional concept in the inner eye of the beholder," construed in a social context, and the dogma of the positive/negative typology has been seriously questioned.

M T ABou-SAlEh

Department of Psychiatry,

Royal Liverpol Hospital,

Liverpool L69 3BX

1 Pasamanick B, Rogers ME, Lilienfield AM. Pregnancy experience and the development of behavior disorders in children. $A m \mathcal{I}$ Psychiatry 1956;112:613-8.

2 Nasrallah HA, McCalley-Whitters M, Jacoby CG. Cerebra ventricular enlargement in young manic males: a controlled CT study. Foumal of Affective Disorders 1982;4:15-9.

Targum SD, Rosen LN, De Lisi LE, Weinburger DR, Citri CM. Cerebral ventricular size in major depressive disorder: an Cssociation with delusional symptoms. Biol Psychiatry 1983;18: 329-36.

\section{Alcohol consumption in England and Wales}

SIR,-Dr G C Dunbar and Mr D D V Morgan describe a survey using a quota sampling method in which interviews took place predominantly "on the street" and which purports to represent the pattern of alcohol consumption in England and 
Wales in 1985 (3 October, p 807). Although quota sampling can be used to produce a sample balanced by age, sex, and social class, it is unlikely that the sample will be unbiased. ${ }^{1}$ The absence of any detail about recruitment procedures and response rates makes assessment of sample validity still more difficult. Moreover, the questionnaire used in the survey asked merely for details of alcohol consumption on a "typical day" in the past week and ignores two difficulties discussed by Wilson" firstly, that alcohol consumption often differs between weekdays and weekends and, secondly, that this is persistently underreported.

The striking inconsistency of the survey's findings with those of earlier studies reinforces our uncertainties about its methods. The authors report that social class has "little important bearing" on alcohol intake. This finding is in direct conflict with that of larger surveys, ${ }^{34}$ which have found a consistent relation between social class and alcohol consumption in men. The questionable inclusion of pensioners (a group with low alcohol intake) in the lowest social group, where alcohol consumption might be expected to be highest, may have contributed to this observation. Moreover, nationwide surveys of expenditure on alcohol ${ }^{5}$ and reported levels of consumption ${ }^{34}$ have suggested that alcohol intakes are much lower in the south east and East Anglia than in other regions, a finding which was not evident on this occasion.

There are obvious differences in methods between the 1985 survey and the 1978 survey $^{2}$ with which it is compared. Wilson used an electoral register sampling method and interviewed subjects in their own homes with a questionnaire designed to obtain information about drinking at particular times of day on each of the last seven days. Without evidence that the sampling procedures produce a similar population and the different questionnaire techniques gain similar responses with respect to alcohol consumption, comparisons between these surveys must be treated with considerable caution, irrespective of their superficial consistency with other indicators.

The quota sampler is, in the words of Yates, "continually looking over his shoulder and wondering whether some extraneous factor exists which will vitiate the conclusions based on his results." We hope that future surveys published by the $B M \mathcal{F}$ will not use quota samples of 926 subjects to represent the entire age, sex, social class, and regional characteristics of Great Britain.

\section{P H WHINCUP}

D G COOK

Department of Clinical Epidemiology

A G SHAPER

and General Practice,

Royal Free Hospital School of Medicine,

London NW3 2 PF

1 Moser CA, Kalton G. Survey methods in social investigation. Aldershot: Gower, 1971:127-37.

2 Wilson P. Drinking in England and Wales. London: HMSO, 1980. (OPCS report SS1128.)

3 Office of Population Censuses and Surveys, Social Survey Division. General household survey, 1984. London: HMSO, 1986.

4 Cummins RO, Shaper AG, Walker M, Wale CJ. Smoking and drinking by middle aged British men: effects of social class and town of residence. BrMed J 1981;283:1497-1502.

5 Central Statistical Office. Regional trends 1986. London: HMSO, 1986:111.

6 Yates F. An experimental study of quota sampling. Fournal of the Royal Statistical Society (Series A) 1953;116:349-405.

\section{Risks and benefits in radiology}

SIR,-Professor J Stewart Orr's leading article (19 September, p 685) highlighted a recent survey by the National Radiological Protection Board which revealed a wide interdepartmental range in radiation doses received by patients in English hospitals. He pointed out that these data are insufficient to show which specific improvements could give the most reduction in unnecessary high doses without any loss of diagnostic information but that unnecessary or inappropriate examinations must be contributory factors.

These important issues underpin several scientific studies which form a continuing research programme being conducted under the auspices of the Royal College of Radiologists. The issue of unnecessary examinations has been addressed in connection with preoperative chest radiography ${ }^{1}$ and also in connection with skull radiography in uncomplicated head injury. ${ }^{23}$ Current initiatives include evaluation of guidelines for selecting patients for 12 categories of radiographic procedures covering some 70 important clinical circumstances. The Medical Research Council funded an observational study of patient exposures in $18 x$ ray departments throughout Wales, which was carried out in 1983-6 to determine the relative importance to patient exposure of differing radiological techniques and to assess their appropriateness. ${ }^{4}$ Analysis of this survey data has led to the formulation of rationalised procedures for the 12 categories of examination studied.

We have already reported on some of the factors mentioned by Professor Orr: "too wide fields," "wasted exposures through errors,"6 and inappropriate choice of projection ${ }^{78}$ for a particular examination. Current research is concentrating initially on implementing guidelines on the above factors, and our data relating to the appropriateness of film-screen combination will facilitate further improvements.

Our scientific studies will underpin the move towards requirements on the choice of medical $x$ ray procedure, although we agree with Professor Orr that much remains to be done.

IAN MatThewS COLIN ROBERTS K T Evans

Convenor of the Royal College of Radiologists working party on effective use of radiology

University of Wales College of Medicine,

Cardiff CF4 4XN

1 Fowkes FGR, Davies ER, Evans KT, et al. Compliance with the Royal College of Radiologists guidelines on the use of preoperative chest radiography. Clin Radiol 1987;38:45-8.

2 Royal College of Radiologists. National study. Patient selection for skull radiography in uncomplicated head injury. Lancet for skull radiog

3 Fowkes FGR, Evans RC, Williams LA, Gelbach SH, Cook BRB, Roberts CJ. Implementation of guidelines for the use of skull radiographs in patients with head injuries. Lancet 1984;ii: 795-6.

4 Matthews IP, Rogers KD. Towards the development of guidelines of practice to reduce patients exposure in diagnostic radiology. Br f Radiol 1986;59:850.

5 Rogers KD, Matthews IP. X-ray field collimation in diagnostic radiology. Radiography 1986;52:161-6.

6 Rogers KD. Matthews IP, Roberts CJ. Variation in repeat rates between 18 radiology departments. $\mathrm{Br} \mathcal{J}$ Radiol 1987; 60:463-8.

7 Matthews IP, Rogers KD, Roberts CJ. Recommended guidelines concerning the choice of projection in examinations of chest, abdomen, pelvis, sinus, cervical spine, lumbar spine, gall abdomen, pelvis, sinus, cervical spine, lumbar spine, gall
bladder and the gastro-intestinal tract and the genitourinary system. Br f Radiol 1987;60:793.

8 Matthews IP, Rogers KD. Changes in procedure for the most frequent radiographic and fluoroscopic examinations in order to prevent radiogenic cancers. Radiography (in press).

\section{Impotence: treatment by autoinjection of} vasoactive drugs

SIR,-Messrs K M Desai and J C Gingell (10 October, p 922) are incorrect to say that there is no scientific evidence to justify the combined therapy of papaverine and phentolamine.

In our own studies the combination of papaverine and phentolamine produced a significantly stronger erection and was associated with a higher in- cidence of spontaneous erections irrespective of the aetiology of the condition. The potentiation of the effects of papaverine by the addition of phentolamine has been shown by Juenemann $e t$ al, whose work the writers cite at the end of their letter but do not refer to in the text. ${ }^{1}$ Combined injection is undoubtedly more expensive but also more effective and it is for this reason that some of their patients with a low penile brachial index did not respond. In our own series only 10 of 287 men with a penile brachial index of $<0.6$ failed to respond to the combination. Combined injections are a very simple way of diagnosing a venous leak, in that all 30 men in our series with a penile brachial index of $>0.7$ who failed to obtain an erection after the intracavernosal injection of papaverine and phentolamine also failed to achieve an erection when the corpora was perfused at flow rates of $>250 \mathrm{ml} / \mathrm{min}$. Using digital subtraction cavernosography we showed that all 30 patients had venous leaks, and with appropriate surgery these patients have a curable cause of impotence.

There are undoubted problems with the penile brachial index as a measure of arterial supply to the penis, but few units will have the facilities to enable them to measure arterial flow more accurately.

GORDON WILLIAMS

Department of Urology,

Hammersmith Hospital,

London W12 OHS

1 Juenemann KP, Lue TF, Fournier GR, Tanagho EA. Haemodynamics of papaverine and phentolamine induced penile erection. $\mathcal{F}$ Urol 1986;136:158-61.

\section{RAWP revisited}

SIR,-Ms Jane Smith's leading article (24 October, p 1015) mentions only briefly why the Resource Allocation Working Party formula has not, and never can, equalise access to health care throughout England. This is because no system exists for the fair and appropriate distribution of funds within a region. That still depends on the "decibel" principle; and consultants with loud voices and plenty of time to use them will always win that game. What we really require is a "DAWP."

Your comment that Bloomsbury Health Authority and North East Thames region might like to build a hospital in the north of England"where the morbidity is"-is well received; but they need not look that far. They need look only to the eastern boundaries of their own region to find poor resources and inadequacies to match those in any deprived northern district.

The most underfunded districts are to be found deep in the rich, overfunded south east. How can a RAWP gaining district gain in a RAWP losing region?

A D Collings

Rochford Hospital,

Rochford, Essex SS4 IRB

SIR,-In her leading article (24 October, p 1015) Ms Jane Smith has made a fashionable assumption. She points out that the recent King's Fund study showed that the workload in central London had been increasing steadily over the past few years without a corresponding increase in doctors and then suggests that "presumably this is because there are still enough doctors to do the work. Thus does supply continue to subvert the definition of need."

The alternative and more likely explanation of the increasing workload is that the local population is becoming older and requires more medical care; in addition there are special groups concentrated in 